\title{
Bone quality assessment of osteogenic cell cultures by Raman microscopy
}

\author{
Gurjit S. Mandair, ${ }^{a *}$ Pieter Steenhuis, ${ }^{a}$ Michael A. Ignelzi $(J r),{ }^{b}$ and Michael D. Morris ${ }^{c}$ \\ a Department of Biologic and Materials Sciences, School of Dentistry, University of \\ Michigan, Ann Arbor, Michigan, 48109, USA \\ ${ }^{b}$ Department of Orthodontics and Pediatric Dentistry, School of Dentistry, The University \\ of North Carolina, Chapel Hill, North Carolina, 27599, USA \\ ${ }^{c}$ Department of Chemistry, University of Michigan, Ann Arbor, Michigan, 48109, USA
}

* Correspondence to: Gurjit S. Mandair, Department of Biologic and Materials Sciences, School of Dentistry, University of Michigan, Michigan, Ann Arbor, USA. Email: gmandair@umich.edu

\begin{abstract}
The use of autologous stem/progenitor cells represents a promising approach to the repair of craniofacial bone defects. The calvarium is recognized as a viable source of stem/progenitor cells that can be transplanted in vitro to form bone. However, it is unclear if bone formed in cell culture is similar in quality to that found in native bone. In this study, the quality of bone mineral formed in osteogenic cell cultures were compared against calvarial bone from postnatal mice. Given the spectroscopic resemblance that exists between cell and collagen spectra, the feasibility of extracting information on cell activity and bone matrix quality were also examined. Stem/progenitor cells isolated from fetal mouse calvaria were cultured onto fused-quartz slides under osteogenic differentiation conditions for 28-days. At specific time intervals, slides were removed and analyzed by Raman microscopy and mineral staining techniques. We show that bone formed in culture at day- 28 resembled calvarial bone from 1-day old postnatal mice with comparable mineralization, mineral crystallinity, and collagen crosslinks ratios. In contrast, bone formed at day-28 contained a lower degree of ordered collagen fibrils compared to 1-day old postnatal bone. Taken together, bone formed in osteogenic cell culture exhibited progressive matrix maturation and mineralization but could not fully replicate the high degree of collagen fibril order found in native bone.
\end{abstract}

Keywords: Raman microscopy, stem cells, osteogenic differentiation, bone quality, tissueengineering

\section{Introduction}

Bone defects, particularly of the craniofacial complex, are a complication of trauma, congenital malformation, or tumor surgery. ${ }^{[1-3]}$ Despite significant advances in craniofacial bone repair, there is an additional risk of bone loss through post-operative bone resorption, infection, abnormal bone healing, or radiotherapy. ${ }^{[3-6]}$ Small bone defects and bone losses can be repaired using autologous bone grafts, but for more extensive repairs and repeated surgeries, alloplastic

This is the author manuscript accepted for publication and has undergone full peer review but has not been through the copyediting, typesetting, pagination and proofreading process, which may lead to differences between this version and the Version of Record. Please cite this article as doi: $10.1002 /$ jrs.5521 
bone substitutes or banked bone allografts can be used. ${ }^{[6,7]}$ Other promising biomaterials for craniofacial bone repair include tissue-engineered constructs, ${ }^{[8]}$ which are ideally seeded with osteogenic stem/progenitor cells sourced from the patient's own body. ${ }^{[9-11]}$ Although, the use of autologous stem/progenitor cells would overcome issues of immunorejection, challenges still remain in identifying suitable human bone-forming cells that meet the clinical need, including the need to assess the quality of bone formed in preclinical models. ${ }^{[7,11-13]}$

Stem/progenitor cell selection and enrichment are two of several important prerequisites that need to be satisfied in developing tissue-engineered therapies for craniofacial bone repair. ${ }^{[14]}$ In mice, the stem cell antigen (Sca-1) is widely used to enrich hematopoietic stem cells, including stem, progenitor, and differentiated cells from a variety of tissue types, such as bone marrow, bone, muscle, cardiac, vascular endothelium, and skin. ${ }^{[15]}$ By combining cell sorting with negative Sca-1 selection, enriched stem and/or progenitor cell fractions can be obtained from neonatal or adult mice. Recent studies have shown that fetal and postnatal mouse calvaria can also provide a source of osteogenic stem/progenitor cells, which can be enriched by negative Sca-1 immunomagnetic selection $\left(\mathrm{Sca}-1^{-}\right) .{ }^{[16,17]} \mathrm{Sca}-1^{-}$cell fractions can form bone in vitro or be loaded into absorbable gelatin sponges and then transplanted into mice to form bone in vivo. ${ }^{[17]}$

Sca-1 expression is known to vary between different mouse strains and tissue types, ${ }^{[12,18]}$ and thus it would be necessary to evaluate their osteogenic potential and the quality of bone formed in vitro. Evaluation of osteogenic potential becomes apparent considering that Sca-1 $1^{-}$and positive Sca-1 $\left(\right.$ Sca- $\left.1^{+}\right)$cell selection can also be used to enrich chondroprogenitor and adipoprogentior cells, respectively, and thus if given the appropriate culture conditions would form their corresponding cartilage and adipose tissue types. ${ }^{[16,17]}$ Current osteogenic assays include alkaline phosphatase (ALP) to detect osteoblastic differentiation and histochemical mineral stains, such as von Kossa and Alizarin Red to quantify phosphate and calcium levels in vitro, respectively. However, mineral stains are non-specific, ${ }^{[19,20]}$ and thus cell culture studies would also benefit from complementary bone quality assessments performed by Raman or FTIR spectroscopy.

Raman spectroscopy can be used to follow the osteogenic differentiation of various cell phenotypes in culture, ${ }^{[21]}$ as well as document the real-time formation and accumulation of bone mineral in cell or organ culture systems. ${ }^{[22,23]}$ In this static time-dependent study, Raman microscopy and mineral stains were used to examine the bone-forming potential of Sca- ${ }^{-}$ stem/progenitor cells derived from fetal mouse calvarias. The relative quantity and maturity of the bone mineral formed over a 28-day culture period was also compared against reference measurements obtained from postnatal calvarial tissues. Given the high plating densities of cells used in this study and their spectroscopic resemblance to type I collagen, the feasibility of using Raman microscopy to assess cell activity and bone matrix quality were also examined.

\section{Materials and methods}

\section{Sca-1 ${ }^{-}$cell isolation, plating, and osteogenic differentiation}


All experiments were approved by the Institutional Animal Care and Use Committee (UCUCA) at the University of Michigan. ${ }^{[16]}$ Fetal-day 18.5-old B6CBAF1/J mice calvarial tissues were harvested and cells obtained by sequential enzymatic digestion. ${ }^{[16]}$ Sca- $1^{-}$cell fractions were plated, expanded, and incubated using standard cell cultivation techniques. ${ }^{[16]}$ Confluent Sca- $1^{-}$ cells were passaged once prior to re-plating at $10,000 \mathrm{cells} / \mathrm{cm}^{2}$ on sterilized fused-quartz slides (S1-UV grade, 12.7-mm circulars, Esco Products, Oak Ridge, NJ). Fused-quartz slides were used because of their low Raman background compared to glass, ${ }^{[24,25]}$ and their ability to maintain cell proliferation and morphology. ${ }^{[26,27]}$ At confluence, expansion media was replaced by osteogenic culture media (DMEM-Low Glucose media containing $2 \%$ fetal bovine calf serum, $10 \mathrm{mM} \beta$-glycerophosphate, $0.1 \mu \mathrm{M}$ dexamethasone, and $0.2 \mathrm{mM}$ ascorbic acid 2-phosphate) to induce osteogenic differentiation. ${ }^{[16,28]}$ The osteogenic media was refreshed every 2-3 days.

\section{Raman microscopy and spectral acquisition}

At the following time intervals: $1,4,8,14,17,25$, and 28-days ( $n=3$ slides per time interval), the osteogenic culture media was removed, quartz slides rinsed once with PBS solution, and fixed with ice-cold $70 \%$ ethanol. ${ }^{[2]}$ After air-drying the slides in a laminar flow hood, they were sampled using Raman microscope equipped with a $785 \mathrm{~nm}$ laser. ${ }^{[25]}$ The spectrograph was fitted with a $50-\mu \mathrm{m}$ slit to provide a spectral resolution of $6-8 \mathrm{~cm}^{-1}$. The excitation laser was spotfocused through a 50x0.80 NA objective (Nikon Instruments, Inc.,) to give $\sim 23 \mathrm{~mW}$ laser power at the sample. The slide was placed onto a gridded reference slide (Electron Microscopy Sciences, Hatfield, PA) to allow the sampled sites to be re-located and re-imaged after von Kossa staining. For each sample slide, 12-18 spectra were acquired from suspected mineralizing sites. Spectra were acquired using 12-min acquisition times. All sample and calibration spectra were processed in MATLAB ${ }^{\circledR}$ Software (The MathWorks Inc., Natick, MA) using locally written scripts. ${ }^{[25]}$

\section{Mineral staining}

After spectral analysis, one set of sample slides were stained for inorganic phosphate using the von Kossa technique described elsewhere. ${ }^{[17]}$ The remaining slides were stained for calcium using a freshly prepared and filtered 1\% Alizarin Red solution ( $\mathrm{pH} \sim 4.2) .{ }^{[29]}$ After 2 mins, the dye solution was removed, and the slides rinsed with deionized water to remove any non-specific binding of the dye to the extracellular matrix (ECM). Mineral formed by Sca- $1^{-}$cells cultured in a single 15-mm-diameter polystyrene well-plate at day-28 was also prepared and stained for calcium. ${ }^{[16]}$ All Alizarin Red stained cell quartz slides and polystyrene well-plate were imaged using a SMZ800 stereomicroscope (Nikon Instruments, Inc.,). 


\section{Spectroscopic reference materials}

Fresh cortical calvarial tissues were harvested from postnatal day-1 (PN1) and postnatal day-56 (PN56) old male B6CBAF1/J mice ( $n=3$ per group). ${ }^{[16,25]}$ Parietal-suture-parietal calvarial tissue sections were isolated, cleaned, and stored in a petri dish containing calcium buffered saline solution at $4{ }^{\circ} \mathrm{C}$. Prior to Raman spectroscopic sampling, the tissue section was placed flat onto a quartz slide. For each tissue section, 6 spectra were acquired from the mineralized cortical parietal regions on either side of the central suture region using the acquisition parameters outlined above. Raman spectra were also acquired from the following reference materials: bovine Achilles type I collagen (Sigma Aldrich Co., St Louis, MO); triglyceride mixtures (Sigma Aldrich Co.,), synthetic powdered hydroxyapatite ( $n=3$, Catalogue \# 289396 with lot numbers: MKBC4763, MKBK2210V, and 06616CS; Sigma Aldrich Co.,); Gly-Pro-Hyp synthetic peptide (Bachem Biosciences Inc., King of Prussia, PA), and calf joint proteoglycan (Elastin Products Co., Inc. Owensville, MO). All materials were used as received, except for the triglycerides in which $4 \mu \mathrm{L}$ aliquots on a fused-quartz slide were allowed to air-dry prior to acquisition.

\section{Curve-fit spectral analysis}

Sample spectra were imported into GRAMS/AI ${ }^{\circledR}$ Software (ThermoGalactic Inc., Salem, NH) for further processing. Briefly, background spectra of bare fused-quartz and sample slides were normalized to the intensity of the silica band at $\sim 786 \mathrm{~cm}^{-1}$, followed by spectral subtraction and smoothing using the Savitisky-Golay function ( $2^{\text {nd }}$ order polynomial, 7-point of smoothing). ${ }^{[24,30]}$ Manual baseline correction was then applied to the $740-1750 \mathrm{~cm}^{-1}$ spectral region, followed by normalization to the intensity of the amide $\mathrm{I} \mathrm{C}=\mathrm{O}$ band at $\sim 1666 \mathrm{~cm}^{-1}$. Spectra showing evidence for bone mineral $\left(\mathrm{ca} \cdot v_{1}\left(\mathrm{PO}_{4}{ }^{3-}\right)\right.$ band between $\left.955-960 \mathrm{~cm}^{-1}\right)$ were separated from spectra containing mainly bone matrix ( $c a$. resolvable $v(\mathrm{C}-\mathrm{C})$ protein backbone band at $\sim 939 \mathrm{~cm}^{-1}$ ). Spectra containing strong lipid $\delta(=\mathrm{CH})$ band at $\sim 1295 \mathrm{~cm}^{-1}$ or glycosaminoglycan $(\mathrm{GAG}) \delta\left(\mathrm{CH}_{3}\right)$ band at $\sim 1378 \mathrm{~cm}^{-1}$ were excluded, owing to their potential overlap with the major matrix proline $v(\mathrm{C}-\mathrm{C})$ and amide $\mathrm{I} v(\mathrm{C}=\mathrm{O})$ bands at $\sim 854$ and $\sim 1666 \mathrm{~cm}^{-1}$, respectively. The sharp band at $\sim 1554 \mathrm{~cm}^{-1}$ in some spectra was identified as an optical artifact, and thus can be ignored.

For curve-fit analysis, second-derivative and constrained Gaussian deconvolution functions were applied to the following spectral regions: 740-910, 900-990, 1185-1400, and 1630-1710 $\mathrm{cm}^{-1}$. Tentative band assignments for the following key osteogenic culture components were made: cell tryptophan (Typ) protein band at $\sim 757 \mathrm{~cm}^{-1}$, cell nucleic acid $v(\mathrm{P}-\mathrm{O}-\mathrm{P})$ band at $\sim 782$ $\mathrm{cm}^{-1}$; matrix proline $v(\mathrm{C}-\mathrm{C})$ band at $\sim 854 \mathrm{~cm}^{-1}$; mineral $v_{1}\left(\mathrm{PO}_{4}{ }^{3-}\right)$ band between $955-960 \mathrm{~cm}^{-1}$; amide III $v(\mathrm{C}-\mathrm{N})+\delta(\mathrm{N}-\mathrm{H})$ bands at $\sim 1246 \mathrm{~cm}^{-1}\left(\alpha\right.$-helical or ordered structure) and $\sim 1264 \mathrm{~cm}^{-1}$ ( $\beta$-sheet or disordered structure); and amide $\mathrm{I} v(\mathrm{C}=\mathrm{O})$ bands at $\sim 1666 \mathrm{~cm}^{-1}$ (non-reducible trivalent collagen crosslinks) and $\sim 1693 \mathrm{~cm}^{-1}$ (reducible divalent collagen crosslinks). ${ }^{[31-33]}$ Band position, bandwidth, and/or intensity ratios between select Raman bands, which contained information on cell activity and bone quality were extracted. ${ }^{[31,34]}$ Briefly, the mineral 
crystallinity parameter was calculated from the bandwidth of the mineral $v_{1}\left(\mathrm{PO}_{4}{ }^{3-}\right)$ band at fullwidth at half maximum $(\mathrm{FWHM}) .{ }^{[31]}$ Mineral/matrix ratios were derived from the mineral $v_{1}\left(\mathrm{PO}_{4}{ }^{3-}\right)$ and proline $v(\mathrm{C}-\mathrm{C})$ band intensities. ${ }^{[27,31,35]}$ Nucleic acid/Typ, collagen disorder/order, and collagen crosslinks ratios were based on: $781 / 854,1246 / 1264$, and $1666 / 1693 \mathrm{~cm}^{-1}$ ratiometric parameters, respectively. ${ }^{[31]}$ Lipid/matrix ratios were not calculated because of the possible dissolution of lipids by ethanol during the fixation step. ${ }^{[34]}$ In addition, given that all spectra were acquired using a high NA-objective, we advise that the intensity of the amide III sub-band at $\sim 1270 \mathrm{~cm}^{-1}$ used to calculate the $1240 / 1270 \mathrm{~cm}^{-1}$ ratios may also exhibit some polarization dependence. ${ }^{[36,37]}$

\section{Statistical analysis}

Statistical analyses were performed in SPSS Statistics Software for Windows (IBM SPSS Statistics Version 24, IBM Corp., NY). All results are presented as means \pm standard derivations (SDs). Due to the small sample size of $n=3$ per group, power analyses between day-8, day-28, PN1, PN56, and/or HA comparisons were performed in nQuery Advisor Software using the Satterhwaite t-test. ${ }^{[38]}$ Only Raman spectroscopic results that were sufficiently powered to claim statistical significances at $80 \%$ power (two-sided, $\alpha=0.05$ ) were reported in this study. Twotailed independent sample t-tests with Bonferroni corrections were then applied to comparisons between day-8, day-28, PN1, PN56, and/or HA groups (34 simultaneous tests). Statistically significant differences were considered at the $p<0.0015(0.05 / 34)$ level. Bar plots and the regression plot were created using the software, Microsoft Excel 2010. The linear correlation between mineral crystallinity and band position of the mineral $v_{1}\left(\mathrm{PO}_{4}{ }^{3-}\right)$ vibration was examined and the $R^{2}$ value and equation of the line reported.

\section{Results and discussion}

\section{Temporal mineralization of Sca-1' cell cultures}

Sca-1 ${ }^{-}$cells took 3-4 days to achieve confluency on fused-quartz slides and displayed normal spindle-to-oval shaped morphologies that were similar to those observed previously on polystyrene plates. ${ }^{[16,17]}$ As shown in Fig. S1a-g, mineral formed by osteogenic Sca- ${ }^{-}$cell cultures were visualized by Alizarin Red staining at various time intervals over the 28-day culture period. Mineral-like deposits were first detected at day- 8 . Thereafter, the frequency, size, and complexity of the mineralized bone nodules increased with culture time. The heterogeneous distribution of the bone nodules was expected given that primary Sca- $1^{-}$cells were passaged only once prior to re-plating, and thus retained their mixed osteogenic stem/progenitor cell phenotypes. ${ }^{[39]}$ The appearance of the bone nodules formed on the quartz slide at day-28 (Fig. $\mathrm{S} 1 \mathrm{~g}$ ) resembled those formed on polystyrene culture plate at day-28 (Fig. S1h) in this study, and in a previous study using the von Kossa staining technique. ${ }^{[16]}$ 


\section{Spectroscopic components of osteogenic cell cultures}

Prior to evaluating the quality of bone formed in culture, it was necessary to spectroscopically characterize the key cell culture components formed under osteogenic differentiation with assistance from mineral staining techniques. Fig. 1 shows the von Kossa stain images taken at specific time intervals over the 28-day culture period with site-matched spectra. As shown in Fig. $1 \mathrm{e}$, cultures were not stained black for inorganic phosphate until day- 8 . The associated spectrum shown in Fig. If contained the distinct mineral $v_{1}\left(\mathrm{PO}_{4}{ }^{3-}\right)$ band at $\sim 958 \mathrm{~cm}^{-1},{ }^{[31]}$ which was absent from the adjacent non-mineralized ECM region. Based on our analyses using reference spectra obtained from type I collagen (Fig. S2a) and synthetic collagen Gly-Pro-Hyp tripeptide (Fig. S2b), spectra obtained between days 1-4 were dominated by cell-specific tryptophan, nucleic acid, and tyrosine bands at 757, 782, and $827 \mathrm{~cm}^{-1}$, respectively. ${ }^{[32,34]}$ No clear collagen-specific bands were found, at least not until significant mineral deposition had occurred. For this reason, the band at $\sim 854 \mathrm{~cm}^{-1}$ was assigned to the collagen proline $v(\mathrm{C}-\mathrm{C})$ vibration between days 8-28, but at earlier time intervals this band would contain greater contributions from cell tyrosine $\delta(\mathrm{C}$ $\mathrm{C}-\mathrm{H})$, valine $v(\mathrm{C}-\mathrm{C})$, and/or polysaccharide $\gamma(\mathrm{C}-\mathrm{O}-\mathrm{C})$ vibrations. ${ }^{[31,}{ }^{32]}$ The extent of spectral mixing between cell and collagen would also depend on the height of the bone nodule from the ECM layer, including the number of cells present at the surfaces or embedded inside the bone nodules. ${ }^{[39-41]}$ Spectral mixing effects may also apply to the amide III, $\mathrm{CH}_{2}$-wag, and amide I regions between $1200-1320,1420-1500$, and $1630-1700 \mathrm{~cm}^{-1}$, respectively. ${ }^{[31]}$

A major lipid cell culture component was also identified. As shown in Fig. S3a-b, a spectrum taken from the poorly mineralized region at day-17 contained bands at 890, 920, 1061, 1128, $1177,1295,1441,1727$, and $1741 \mathrm{~cm}^{-1}$. These bands were characteristic of triglycerides and their band positions coincided with those shown in the reference spectrum of the triglyceride mixture in Fig. S2c and those reported in the literature. ${ }^{[42]}$ Although, bone triglycerides have been detected by chromatography ${ }^{[43]}$ and NMR spectroscopy ${ }^{[44]}$ this is the first study in which they have been detected under osteogenic differentiation conditions by Raman microscopy. Previous studies have shown that primary osteogenic Sca- $1^{-}$cells have some limited capacity to form lipid vacuoles after 21-days under adiopogenic differentiation conditions. ${ }^{[17]}$ These findings support other studies, which have proposed that osteogenic cell lineages can also produce lipids. ${ }^{[45,46]}$

Spectra acquired from the more granular region at day-14 (Fig. S3c-d) also gave rise to additional set of bands that were distinct from cell proteins, bone mineral, and triglycerides. The bands at $854,939,1045,1081,1125,1339$, and $1419 \mathrm{~cm}^{-1}$ resembled type I collagen, but were more pronounced, whereas the $\mathrm{CH}_{2}$-wag band between $1452-1458 \mathrm{~cm}^{-1}$ was broader and more symmetrical when compared to that typically encountered for type I collagen (Fig. S2a). The band at $\sim 1377 \mathrm{~cm}^{-1}$ in Fig. S3e was also not typical of type I collagen. As shown in Fig. S3d, the von Kossa image acquired from the granular region was not stained for inorganic phosphate and thus indicated the presence of a soluble ECM component. We propose that some of these 
additional bands, especially the band at $1377 \mathrm{~cm}^{-1}$ originated from the $\delta\left(\mathrm{CH}_{3}\right)$ bending mode of proteoglycans and/or glycosaminoglycans (GAGs), which have been reported to occur at $\sim 1375$ $\mathrm{cm}^{-1}$ in subchondral bone. ${ }^{[33]}$ The presence of proteoglycans and/or GAGs in our osteogenic cultures was also supported by the reference spectrum obtained from proteoglycan (Fig. S3d), which also contained the $\delta\left(\mathrm{CH}_{3}\right)$ band at $\sim 1374 \mathrm{~cm}^{-1}$. More importantly, proteoglycans and GAGs are known to be expressed by calvarial tissues and pre-osteoblast cells, owing to their importance in mediating cell proliferation and differentiation activities, as well as mineralization in an inhibitory and/or stimulatory manner. ${ }^{[47-50]}$

After key cell culture components had been characterized, curve-fit analyses were performed to extract information on cell activity and mineralization. The phase of the mineral formed in culture was also examined using the mineral crystallinity parameter and the mineral $v_{1}\left(\mathrm{PO}_{4}{ }^{3-}\right)$ band position, whereas collagen crosslinks and disorder/order ratios were used to evaluate the quality of the matrix. These spectroscopic parameters will be discussed in turn, including how bone formed at day-28 compared to that of calvarial tissues obtained from postnatal mice at day1 (PN1) and day-56 (PN56).

\section{Nucleic acid/protein ratios}

Cell activities were evaluated using nucleic acid/protein ratios, which had previously been used to determine the differentiation and/or proliferation status of embryonic stem cells and primary mouse osteoblast cells. ${ }^{[27,51]}$ Nucleic acid/protein ratios can be obtained from the ratio of the cell nucleic acid $v(\mathrm{O}-\mathrm{P}-\mathrm{O})$ band at $\sim 782 \mathrm{~cm}^{-1}$ to one of the cell protein tryptophan (Typ), proline (Pro) or general matrix $\mathrm{CH}_{2}$-wag bands at 757,853 , or $1450 \mathrm{~cm}^{-1}$, respectively. ${ }^{[27,34,51]}$ Given that Sca- ${ }^{-}$cell cultures would eventually produce collagen and triglyceride components, nucleic acid/Typ ratio was considered as the most representative measure of early cell activity. As shown in Fig. 2a, nucleic acid/Typ ratios declined dramatically after day-1 because of the increased differentiation of Sca-1- ${ }^{-}$osteoprogenitor/stem cells into the more mature osteoblast cell phenotype. The decline in nucleic acid/Typ ratios is most likely explained by increased matrix synthesis with differentiation, with DNA levels remaining constant as cell proliferation is downregulated. ${ }^{[52]}$ Given that mineral deposition was first detected at day-8, the down-regulation in cell proliferation would have occurred prior to this time point. Although, nucleic acid/Typ ratios appeared to decline consistently throughout the 28-day culture period, we advise against using this parameter once significant mineralization has occurred because: (1) the down-regulation in cell proliferation is linked to increased matrix synthesis ${ }^{[52]}$ and that (2) with increased incubation time, the cell-specific Typ protein band at $757 \mathrm{~cm}^{-1}$ would gain greater spectral contributions from collagen.

\section{Mineral/matrix ratios}


The mineralization of osteogenic cultures was evaluated using mineral/matrix ratios derived from the mineral $v_{1}\left(\mathrm{PO}_{4}{ }^{3-}\right)$ band between $955-960 \mathrm{~cm}^{-1}$ and the matrix proline band at $853 \mathrm{~cm}^{-1}$. As shown in Fig. 2b, mineral was not detected spectroscopically until day-8, which was later confirmed by von Kossa staining (Fig. 1e-f). However, mineralization decreased on day-14, but then increased again between days 17-28. This bimodal mineralization behavior contrasts with the linear mineralization trends reported throughout the 28-day culture period for human primary osteoblast ( $\mathrm{HOb})$ and osteoblast-like U20S cells. ${ }^{[53]}$ The bimodal mineralization trend found in this study could in part be attributed to the limited number of Raman spectroscopic measurements that can be obtained from suspected mineralizing sites for a given slide when compared to mineral staining techniques. Although, the amount of mineral formed at day-14 (Fig 2b) was considered low compared to mineral formed at other time intervals (Fig. 2b), it still coincided with the time point in which osteogenic Sca- $1^{-}$cell cultures had previously been shown to express the osteogenic markers, alkaline phosphatase (ALP) and Runt-related transcription factor 2 (Runx2). ${ }^{[16]}$

The amount of mineral formed in vitro at day- 28 was comparable to that found in native calvarial tissue from PN1 mice (Fig. 2b). The latter result was supported by a previous X-ray and FTIR spectroscopic study, whereby the extent of calcification formed in a 30-day old osteoblast cell culture model, derived from embryonic chick calvaria, was similar to that found in late chick embryonic tissue and early chick postnatal tibiae. ${ }^{[54]}$ In another X-ray and FTIR spectroscopic study, the mineral phase between 12-day old MC3T3-E1 osteoblast cell cultures and 30-day old mouse calvarial tissues were also reported to be similar. ${ }^{[19]}$

In contrast, the reason into why the mineral/matrix ratio of PN56 mice trended lower compared to PN1 mice and mineral formed in vitro at day-28 was not initially apparent (Fig. 2b). In a previous Raman spectroscopic study, calvarial tissues from PN1, PN3, PN7, and PN14 mice exhibited similar mineral/matrix ratios ( $c$. $960 / 1665 \mathrm{~cm}^{-1}$ ratios), but the ratios were still significantly lower when compared to 6-month old calvarial tissue. ${ }^{[5]}$ Interestingly, another study reported that trypsinized collagen extracts from 6-month old mouse calvarial tissue were not completely mineralized, indicating that non-mineralized areas co-existed next to mineralized collagen. ${ }^{[56]}$ We conjecture that the low mineral/matrix ratio exhibited by PN56 mice was the result of incomplete mineralization of parietal bone. More specifically, the cranial vault of PN56 mice may have still been expanding to accommodate the growing brain, ${ }^{[57]}$ and therefore new parietal bone formed outwards from the sagittal suture region may not have been completely mineralized, leading to lower mineral/matrix ratios.

Although the current study and prior work have primarily focused on evaluating the mineralization capacity specific to Sca- $1^{-}$cells under osteogenic differentiation conditions, ${ }^{[16,17]}$ studies into how this in vitro osteogenic model compares with other established osteoblast cell lines or primary cell cultures have yet to be performed ${ }^{[58,59]}$ Notwithstanding, the immortalized pre-osteoblast MC3T3-E1 cell line has also been shown to express the stem cell marker, Sca-1, which is not unexpected given that this cell line is also derived from newborn mouse calvaria. ${ }^{[18]}$ Given that both Sca-1 ${ }^{-}$and MC3T3-E1 cells also express the early osteogenic differentiation 
markers, Runx2 and ALP, [16, 17, 60] suggest that these cell phenotypes would share similar mineralization outcomes in vitro. While MC3T3-E1 cell cultures exhibit cell proliferation rates and mineralization outcomes that were comparable to those reported for primary HOb cells, ALP activity and Runx2 gene expression were, however, significantly different because of speciesspecific differences. ${ }^{[60]}$ On the other hand, continuous cell passaging studies have shown that MC3T3-E1 cells can retain their osteogenic capacity up to 30 -passages, ${ }^{[61]}$ while Sca- $1^{-}$cells lose their ability to differentiate into bone at 6-passages. ${ }^{[16]}$ Further comparative studies would still be needed to ascertain whether the limited self-renewal capacity exhibited by the Sca-1 ${ }^{-}$in vitro osteogenic model would better reflect the inherent heterogeneity exhibited by bone formed in vitro by primary $\mathrm{HOb}$ cells. ${ }^{[59]}$

\section{Mineral crystallinity and mineral phase}

In bone Raman spectroscopy, bandwidths of the mineral $v_{1}\left(\mathrm{PO}_{4}{ }^{3-}\right)$ peaks can convey information on mineral crystallinity, with narrower bandwidths reflecting more ordered mineral crystallites. ${ }^{[62]}$ Moreover, Raman measure of mineral crystallinity has been shown to be linearly correlated with: (1) mineral crystal size measurements obtained by X-ray diffraction, ${ }^{[63,64]}$ and (2) percent of $B$-type carbonate $\left(\mathrm{CO}_{3}\right)$ content of synthetic carbonated hydroxyapatites $\left(0.3-8 \% \mathrm{CO}_{3}\right){ }^{[65,66]}$ As discussed previously, bone mineral was not detected until day- 8 and therefore the bandwidth measurements shown at day- 1 and day-4 in Fig. $2 \mathrm{c}\left(13.9 \pm 3.3\right.$ and $13.8 \pm 0.5 \mathrm{~cm}^{-1}$, respectively) reflect those of the faint ECM matrix band and not of actual bone mineral. As shown in Fig. 2c, mineral formed at day- 8 was found to be crystalline $\left(17.8 \pm 1.2 \mathrm{~cm}^{-1}\right)$, but still within the ranges found for native calvarial bone from PN1 and P56 mice $\left(15.4 \pm 0.4\right.$ and $18.6 \pm 0.2 \mathrm{~cm}^{-1}$, respectively), At days-14, -17 , and -25 , bone mineral became less crystalline $(24.0 \pm 0.5,23.7 \pm$ 0.5 , and $22.5 \pm 4.0 \mathrm{~cm}^{-1}$, respectively). At day-28, bone mineral crystallinity $\left(17.8 \pm 0.5 \mathrm{~cm}^{-1}\right)$ was comparable to PN1 and PN56 mice. Narrower ranges in mineral crystallinity values reported for certain osteoblast-like cell lines have, in part, been associated with dystrophic mineral precipitations. ${ }^{[53]}$ However, cell culture and postnatal mineral crystallinity measurements found in this study were considerably broader when compared to synthetic hydroxyapatite standard (HA, $\left.10.1 \pm 0.01 \mathrm{~cm}^{-1}\right)$.

With temporal variations in bone mineral crystallinity shown in Fig. 2c, one would also expect to find variations in the corresponding mineral $v_{1}\left(\mathrm{PO}_{4}{ }^{3-}\right)$ band positions. In our previous study involving the in vitro intramembranous mineralization of calvarial tissues from fetal-day 18.5old mice, we found that band positions at $\sim 955 \mathrm{~cm}^{-1}$ was indicative of octacalcium phosphate (OCP)-like mineral phases, whereas band positions between $957-962 \mathrm{~cm}^{-1}$ reflected more mature, carbonated-apatitic mineral phases. ${ }^{[25]}$ The temporal maturation of precursor mineral phases has been reported in other osteogenic models. ${ }^{[27,67]}$ By regressing the mineral crystallinity parameter against band positions gave rise to a significant and positive linear correlation $\left(R^{2}=\right.$ $0.87, p<0.001$ ) (Fig. 2d). The plot shows that mineral phases formed in culture at days 8 and 28 and in calvarial tissue from PN1 and PN56 mice were mature. In contrast, mineral phases formed 
in culture at days 14, 17, and 25 were less mature and more OCP-like. The regression plot also included the hydroxyapatite standard, which was found to be highly crystalline. However, as shown in Fig. S2e, the hydroxyapatite standard was deficient in $B$-type carbonate substitution unlike bone mineral formed at day-28 (Fig. 1n) and calvarial tissue from PN1 and PN56 mice (Fig. S2f-g), which contained the $v_{1}\left(\mathrm{CO}_{3}{ }^{2-}\right)$ band at $\sim 1070 \mathrm{~cm}^{-1}$. Taken together, we show that mineral crystallinity is strongly related with the phase of the mineral formed in culture.

\section{Collagen crosslinks ratio}

The quality of bone matrix and the degree of mineral formed in vivo are linked to the relative divalent to trivalent collagen crosslinks content. ${ }^{[68]}$ Divalent collagen crosslinks are reducible intermediates, which include dehydro-dihydroxylysinonorleucine (deH-DHLNL) and dehydrohydroxylysinonorleucine (deH-HLNL). ${ }^{[69]}$ With time, these divalent collagen crosslinks mature into the more stable trivalent collagen crosslinks, which include pyridinoline (PYD) and deoxypyridinoline (DPD), amongst others. ${ }^{[70]}$ The relative amounts of trivalent (PYD) to divalent (deH-DHLNL) collagen crosslinks can be estimated spectroscopically from the ratio of the deconvolved amide I bands at $\sim 1667 \mathrm{~cm}^{-1}$ and $\sim 1693 \mathrm{~cm}^{-1}$, respectively. ${ }^{[71]}$ At present, spectroscopic measures of collagen crosslinks ratios have predominantly been obtained from mineralizing and non-mineralizing MC3T3-E1 osteoblastic cell line. ${ }^{[72-74]}$ As shown in Fig. 2e, collagen crosslinks ratios were unremarkably consistent throughout the 28-day culture period, with the exception of the large variation observed at day-4. In general, collagen crosslinks ratio found at day-28 was comparable to that found in calvarial tissue from PN1 mice, but was nonsignificantly lower when compared to PN56 mice. Although, age-related changes in collagen crosslink content in calvarial tissues from postnatal mice have yet to be examined, recent chromatographic analyses have shown that calvarial tissues obtained from adult mice contained higher amounts of immature collagen crosslinks compared to long bones. ${ }^{[75,76]}$ In addition, older calvarial tissues have been reported to exhibit higher osteoclastic activity compared to long bones, which could in part explain why collagen crosslinks ratios found in PN56 mice were considerably lower when compared to PN1 mice.

\section{Collagen disorder/order ratio}

The spectral region between 1200 and $1300 \mathrm{~cm}^{-1}$ was also found to contain information on the conformation of proteins expressed by Sca- $1^{-}$cells, either internally or externally. As shown in Fig. 2f the ratio between the amide III sub-bands at $\sim 1246 \mathrm{~cm}^{-1}(\beta$-sheet, disordered structure) and $\sim 1264 \mathrm{~cm}^{-1}$ ( $\alpha$-helix, ordered structure) ${ }^{[32,34]}$ were used to evaluate: (1) the relative amounts of disordered to ordered proteins expressed by Sca- $1^{-}$cells between days 1-4, and (2) the structural organization of the collagenous matrix during the mineralization phase through days 828. Firstly, the high initial disorder/order ratio displayed at day-1 was attributed to the high initial expression of disordered proteins by Sca-1 ${ }^{-}$cells. This was not entirely unexpected given 
that osteogenic cultures were known to be more active during the early cell proliferation phase. ${ }^{[52]}$ While changes in cell protein conformations are essential for the normal functioning of cell processes, ${ }^{[77,78]}$ we speculate that the reduced disorder/order ratio found at day-4 was attributed to the increased expression of more ordered proteins by Sca- $1^{-}$cells. More ordered proteins would also include $\alpha$-helical collagen, which is known to be formed within days of osteogenic induction in culture. ${ }^{[52,79,80]}$ The disorder/order ratios continued to decline steadily through days 8-28, which was facilitated by the progressive stabilization and co-alignment of the collagen fibrils with the apatitic mineral crystallites. Interestingly, the disorder/order ratio found in culture at day-28 was significantly higher than those of calvarial tissue from PN1 and PN56 mice. These differences could in part be explained by the fact that bone mineral formed in 2dimensional osteogenic cell cultures do not fully capture the hierarchical or anisotropic collagen organization found in native bone. ${ }^{[81-83]} \mathrm{A}$ recent in situ second-harmonic-generation (SHG) study has also shown that collagen fibers produced by pre-osteoblast MC3T3-E1 cell cultures are in general less structured and nonspecifically orientated due to immature structure. ${ }^{[84]}$ In addition, the collagen amide III band at $\sim 1270 \mathrm{~cm}^{-1}$ is known to be strongly polarization dependent compared to the $\sim 1240 \mathrm{~cm}^{-1}$ band, ${ }^{[36,37]}$ and therefore would be more sensitive to the orientation of collagen fibrils, especially in native bone. It has recently been shown that the orientation and alignment of cells in osteogenic culture can be increased by using artificiallyorientated collagen scaffolds ${ }^{[85]}$ or by mechanical stimulation. ${ }^{[86]}$ These tissue-engineering approaches could be employed to provide tissues with the higher degree of anisotropic collagen found in native bone.

\section{Limitation of the current study}

While mineral crystallinity of bone formed by Sca- $1^{-}$cell cultures and postnatal bone were found to be linearly correlated with mineral band position (Fig. 2d), the high initial mineral/matrix ratios observed at day-8 (Fig. 2b) still requires further investigation. More specifically, the current study would have benefited from additional replicate experiments to determine whether the high initial mineral/matrix ratios observed at day- 8 was an outlier or related to the normal biological variation inherent to Sca- $1^{-}$stem/progenitor cells isolated fetal mouse calvarial tissues. Previous in vivo organ culture spectroscopic studies have also shown that the mineralization and mineral crystallinity kinetics of neonatal mouse calvarias are different. In the latter study, mineral/matrix ratios was found to increase in aperiodic step-like increments over a 6-day period, whereas mineral crystallinity increased linearly before reaching a plateau around day-3. ${ }^{[23]}$

\section{Conclusions}

The current work shows that osteogenic cell cultures, enriched by calvarial-derived Sca- ${ }^{-}$ stem/progenitor cells, can produce bone that is comparable to 1-day old postnatal bone in terms of mineralization, mineral crystallinity, and collagen crosslink ratios. Additional new insights 
into the mineral phase of the cell cultures could be obtained by regressing the mineral crystallinity parameter against the mineral band position. Raman spectra of osteogenic cell cultures were found to be considerably more complex with the detection of additional triglyceride and glycosaminoglycan-like components. Through the characterization of cell- and collagen-specific vibrational modes, we show that the down-regulation of cell activity preceded mineralization. However, osteogenic cell cultures could not fully replicate the high degree of collagen fibril order found in native bone. Further investigation into using orientated collagen scaffolds or mechanical stimulation maybe required to produce bone with increased collagen fibril order that is inherent to native bone. In conclusion, our data provides new insights into the composition of osteogenic cell cultures and the quality of mineral and matrix formed by Sca- $1^{-}$ stem/progenitor cells. Raman spectroscopic measures of bone quality used in this study could equally be used to evaluate ex vivo specimens obtained from preclinical models that are used in tissue engineering research.

\section{Author contributions}

Authors' roles: Study concept, design, and provision of study materials: MDM and MAI. Sca-1 ${ }^{-}$ cell culture model development: MAI and PS. Cell isolation and culturing: PS. Histochemistry: PS, GSM. Raman data collection and analysis: GSM. Data interpretation: GSM, PS, MDM, and MAI. Manuscript writing: GSM, PS, and MDM.

\section{Conflicts of interest}

The authors report no conflicts of interest. Pieter Steenhuis performed all experiments at the University of Michigan prior to his employment at Sysmex Europe GmbH, Germany.

\section{Acknowledgements}

This work was supported by NIH grants R01 AR047969 (GSM, MDM) and DE11530 (PS, MAI). GSM also acknowledges partial support by NIH grant P30 AR069620 (Karl J. Jepsen, PI; David H. Kohn, Core Director of the Michigan Integrative Musculoskeletal Health Core Center or MiMHC). GSM thanks Genevieve Romanowicz, Eric Madsen, and Dr. David Kohn of the School of Dentistry for providing the 2-month old postnatal mice calvaria and with assistance in performing negative control cell culture experiments, as well as Drs. Chunxi Ge and Renny Franceschi of the School of Dentistry for providing 1-day old postnatal mice calvaria tissues and for discussions. GSM also thanks Drs. Victoria Popescu, Kurtulus Golcuk, and Karen EsmondeWhite of the Department of Chemistry for their initial critique of this work.

\section{References}

[1] V. Allareddy, R. P. Nalliah, J. Oral Maxillofac. Surg. 2011; 69, 2613. 
[2] A. O. M. Wilkie, G. M. Morriss-Kay, Nat. Rev. Genet. 2001; 2, 458.

[3] E. I. Lee, A. H. Chao, R. J. Skoracki, P. R. Yu, F. DeMonte, M. M. Hanasono, Plast. Reconstr. Surg. 2014; $133,675$.

[4] S. N. Khan, F. P. Cammisa, H. S. Sandha, A. D. Diwan, F. P. Girardi, J. M. Lane, J. Am. Acad. Orthop. Surg. 2005; 13, 77.

[5] M. A. Riordan, V. M. Simpson, W. A. Hall, World Neurosurg. 2016; 87, 207.

[6] D. J. Bonda, S. Manjila, W. R. Selman, D. Dean, Neurosurgery 2015; 77, 814.

[7] B. A. Fishero, N. Kohli, A. Das, J. J. Christophel, Q. J. Cui, Craniomaxillofac Trauma Reconstr. $2015 ; 8,23$.

[8] E. S. Place, N. D. Evans, M. M. Stevens, Nat. Mater. 2009; 8, 457.

[9] L. Santos-Ruiz, D. J. Mowatt, A. Marguerie, D. Tukiainen, M. Kellomaki, P. Tormala, E. Suokas, H. Arstila, N. Ashanunakhi, P. Ferretti, J. Tissue Eng. Regen. Med. 2007; 1, 199.

[10] D. Marolt, M. Knezevic, G. V. Novakovic, Stem Cell Res. Ther. $2010 ; 1$.

[11] B. Levi, J. P. Glotzbach, V. W. Wong, E. R. Nelson, J. Hyun, D. C. Wan, G. C. Gurtner, M. T. Longaker, J. Craniofac. Surg. 2012; 23, 319.

[12] F. Anjos-Afonso, D. Bonnet, Best Pract. Res., Clin. Haematol. 2011; 24, 13.

[13] J. A. Helms, R. R. Amasha, P. Leucht, Bone 2007; 41, 479.

[14] F. M. Chen, L. A. Wu, M. Zhang, R. Zhang, H. H. Sun, Biomaterials 2011; 32, 3189.

[15] C. Holmes, W. L. Stanford, Stem Cells 2007; 25, 1339.

[16] P. Steenhuis, G. J. Pettway, M. A. Ignelzi, Calcif. Tissue Int. 2008; 82, 44.

[17] P. Steenhuis, K. M. Carr, G. J. Pettway, M. A. Ignelzi, Cells Tissues Organs 2009; 190, 150.

[18] M. C. Horowitz, A. Fields, D. Demeo, H. Y. Qian, A. L. M. Bothwell, E. Trepman, Endocrinology 1994; $135,1032$.

[19] W. N. Addison, V. Nelea, F. Chicatun, Y. C. Chien, N. Tran-Khanh, M. D. Buschmann, S. N. Nazhat, M. T. Kaartinen, H. Vali, M. M. Tecklenburg, R. T. Franceschi, M. D. McKee, Bone 2015; $71,244$.

[20] L. F. Bonewald, S. E. Harris, J. Rosser, M. R. Dallas, S. L. Dallas, N. P. Camacho, B. Boyan, A. Boskey, Calcif. Tissue Int. 2003; 72, 537.

[21] C. C. Moura, R. S. Tare, R. O. C. Oreffo, S. Mahajan, J. R. Soc., Interface 2016; 13.

[22] A. Hashimoto, L. D. Chiu, K. Sawada, T. Ikeuchi, K. Fujita, M. Takedachi, Y. Yamaguchi, S. Kawata, S. Murakami, E. Tamiya, J. Raman Spectrosc. 2014; 45, 157.

[23] J. D. P. McElderry, G. S. Zhao, A. Khmaladze, C. G. Wilson, R. T. Franceschi, M. D. Morris, J. Bone Miner. Res. 2013; 28, 1846.

[24] P. S. Hung, Y. C. Kuo, H. G. Chen, H. H. K. Chiang, O. K. S. Lee, PLoS One 2013; 8.

[25] N. J. Crane, V. Popescu, M. D. Morris, P. Steenhuis, M. A. Ignelzi, Jr., Bone 2006; 39, 434.

[26] F. Draux, P. Jeannesson, A. Beljebbar, A. Tfayli, N. Fourre, M. Manfait, J. Sule-Suso, G. D. Sockalingum, Analyst 2009; 134, 542.

[27] S. J. Smith, R. Emery, A. Pitsillides, C. E. Clarkin, S. Mahajan, Analyst 2017; 142, 1962.

[28] L. Lammers, C. Naujoks, K. Berr, R. Depprich, N. Kubler, U. Meyer, F. Langenbach, B. Luttenberg, G. Kogler, H. P. Wiesmann, J. Handschel, Stem Cell Res. 2012; 8, 193.

[29] C. A. Luppen, E. Smith, L. Spevak, A. L. Boskey, B. Frenkel, J. Bone Miner. Res. 2003; 18, 1186. 
[30] L. L. McManus, G. A. Burke, M. M. McCafferty, P. O'Hare, M. Modreanu, A. R. Boyd, B. J. Meenan, Analyst 2011; 136, 2471.

[31] G. S. Mandair, M. D. Morris, BoneKEy Rep. 2015; 4.

[32] Z. Movasaghi, S. Rehman, I. U. Rehman, Appl. Spectrosc. Rev. 2007; 42, 493.

[33] S. Gamsjaeger, K. Klaushofer, E. P. Paschalis, J. Raman Spectrosc. 2014; 45, 794.

[34] G. S. Mandair, A. L. Han, E. T. Keller, M. D. Morris, J. Biomed. Opt. 2016; 21.

[35] C. Y. Wang, Y. Wang, N. T. Huffman, C. Y. Cui, X. M. Yao, S. Midura, R. J. Midura, J. P. Gorski, J. Biol. Chem. 2009; 284, 7100.

[36] A. Bonifacio, V. Sergo, Vib. Spectrosc. 2010; 53, 314.

[37] T. Colard, G. Falgayrac, B. Bertrand, S. Naji, O. Devos, C. Balsack, Y. Delannoy, G. Penel, PLoS One 2016; 11.

[38] D. R. Rux, J. Y. Song, K. M. Pineault, G. S. Mandair, I. T. Swinehart, A. J. Schlientz, K. N. Garthus, S. A. Goldstein, K. M. Kozloff, D. M. Wellik, J. Bone Miner. Res. 2017; 32, 1750.

[39] N. Fratzl-Zelman, P. Fratzl, H. Horandner, B. Grabner, F. Varga, A. Ellinger, K. Klaushofer, Bone 1998; 23, 511.

[40] K. Satomura, M. Nagayama, Acta Anat. 1991; 142, 97.

[41] M. E. Marsh, A. M. Munne, J. J. Vogel, Y. Q. Cui, R. T. Franceschi, J. Bone Miner. Res. 1995; 10, 1635.

[42] C. Krafft, L. Neudert, T. Simat, R. Salzer, Spectrochim. Acta, Part A 2005; 61, 1529.

[43] A. During, G. Penel, P. Hardouin, Prog. Lipid Res. 2015; 59, 126.

[44] K. H. Mroue, J. D. Xu, P. Z. Zhu, M. D. Morris, A. Ramamoorthy, Phys. Chem. Chem. Phys. 2016; $18,18687$.

[45] D. M. Wen, C. Androjna, A. Vasanji, J. Belovich, R. Midura, Ann. Biomed. Eng. 2010; 38, 558.

[46] Y. Tintut, L. L. Demer, Trends Endocrinol. Metab. 2014; 25, 53.

[47] H. Nakamura, A. Hirata, T. Tsuji, T. Yamamoto, Arch. Histol. Cytol. 2001; 64, 109.

[48] P. Blumberg, R. Brenner, S. Budny, H. Kresse, Calcif. Tissue Int. 1997; 60, 554.

[49] K. J. Manton, L. M. Haupt, K. Vengadasalam, V. Nurcombe, S. M. Cool, J. Mol. Histol. 2007; 38, 415.

[50] H. D. Nah, M. Pacifici, L. C. Gerstenfeld, S. L. Adams, T. Kirsch, J. Bone Miner. Res. 2000; 15, 522.

[51] H. G. Schulze, S. O. Konorov, N. J. Caron, J. M. Piret, M. W. Blades, R. F. B. Turner, Anal. Chem. 2010; $82,5020$.

[52] G. S. Stein, J. B. Lian, T. A. Owen, FASEB J. 1990; 4, 3111.

[53] L. L. McManus, F. Bonnier, G. A. Burke, B. J. Meenan, A. R. Boyd, H. J. Byrne, Analyst 2012; 137, 1559.

[54] C. Rey, H. M. Kim, L. Gerstenfeld, M. J. Glimcher, Connect. Tissue Res. 1996; 35, 343.

[55] C. P. Tarnowski, M. A. Ignelzi, M. D. Morris, J. Bone Miner. Res. 2002; 17, 1118.

[56] B. Zimmermann, A. Moegelin, P. de Souza, J. Bier, Anat. Embryol. 1998; 197, 155.

[57] K. A. Lenton, R. P. Nacamuli, D. C. Wan, J. A. Helms, M. T. Longaker, Curr. Top Dev. Biol. 2005; 66, 287.

[58] S. Zhu, S. Ehnert, M. Rouß, V. Häussling, R. Aspera-Werz, T. Chen, A. Nussler, Int. J. Mol. Sci. 2018; 19, 2284.

[59] E. M. Czekanska, M. J. Stoddart, R. G. Richards, J. S. Hayes, Eur. Cells Mater. 2012; 24, 1. 
[60] E. M. Czekanska, M. J. Stoddart, J. R. Ralphs, R. G. Richards, J. S. Hayes, J. Biomed. Mater. Res., Part A 2014; 102, 2636.

[61] X. Z. Yan, W. X. Yang, F. Yang, M. Kersten-Niessen, J. A. Jansen, S. K. Both, Tissue Eng., Part C 2014; $20,198$.

[62] J. J. Freeman, B. Wopenka, M. J. Silva, J. D. Pasteris, Calcif. Tissue Int. 2001; 68, 156.

[63] Y. Sa, Y. R. Guo, X. W. Feng, M. Wang, P. Li, Y. X. Gao, X. Yang, T. Jiang, New J. Chem. 2017; $41,5723$.

[64] H. Aguiar, S. Chiussi, M. Lopez-Alvarez, P. Gonzalez, J. Serra, Ceram. Int. 2018; 44, 495.

[65] M. M. Wang, R. Qian, M. Bao, C. X. Gu, P. Z. Zhu, Mater. Lett. 2018; 210, 203.

[66] A. Awonusi, M. D. Morris, M. M. J. Tecklenburg, Calcif. Tissue Int. 2007; 81, 46.

[67] M. Bennet, A. Akiva, D. Faivre, G. Malkinson, K. Yaniv, S. Abdelilah-Seyfried, P. Fratzl, A. Masic, Biophys. J. 2014; 106, L17.

[68] M. Saito, K. Marumo, Osteoporosis Int. 2010; 21, 195.

[69] T. J. Sims, N. C. Avery, A. J. Bailey, in Extracellular Matrix Protocols, (Eds: C. H. Streuli, M. E. Grant), Humana Press, Totowa, New Jersey, 2000, pp. 11.

[70] E. P. Paschalis, S. Gamsjaeger, D. N. Tatakis, N. Hassler, S. P. Robins, K. Klaushofer, Calcif. Tissue Int. 2015; 96, 18.

[71] E. P. Paschalis, K. Verdelis, S. B. Doty, A. L. Boskey, R. Mendelsohn, M. Yamauchi, J. Bone Miner. Res. 2001; 16, 1821.

[72] Y. Z. Meng, M. E. Faillace, K. Dorst, S. J. Palmaccio, L. M. Miller, Y. X. Qin, Biointerphases 2017; 12.

[73] S. P. Canelon, J. M. Wallace, PLoS One 2016; 11.

[74] E. M. B. McNerny, B. Gong, M. D. Morris, D. H. Kohn, J. Bone Miner. Res. 2015; 30, 446.

[75] T. van den Bos, D. Speijer, R. A. Bank, D. Bromme, V. Everts, Bone 2008; 43, 459.

[76] T. Matsuura, K. Tokutomi, M. Sasaki, M. Katafuchi, E. Mizumachi, H. Sato, BioMed Res. Int. 2014.

[77] F.-X. Theillet, A. Binolfi, T. Frembgen-Kesner, K. Hingorani, M. Sarkar, C. Kyne, C. Li, P. B. Crowley, L. Gierasch, G. J. Pielak, A. H. Elcock, A. Gershenson, P. Selenko, Chem. Rev. (Washington, DC, U. S.) 2014; 114, 6661.

[78] S. R. Panikkanvalappil, S. M. Hira, M. A. Mahmoud, M. A. El-Sayed, J. Am. Chem. Soc. 2014; 136, 15961.

[79] R. T. Franceschi, B. S. Iyer, J. Bone Miner. Res. 1992; 7, 235.

[80] L. D. Quarles, D. A. Yohay, L. W. Lever, R. Caton, R. J. Wenstrup, J. Bone Miner. Res. 1992; 7 , 683.

[81] B. G. Matthews, D. Naot, K. E. Callon, D. S. Musson, R. Locklin, P. A. Hulley, A. Grey, J. Cornish, BoneKEy Rep. 2014; 3, 560.

[82] D. Zujur, K. Kanke, A. C. Lichtler, H. Hojo, U. Chung, S. Ohba, Sci. Adv. 2017; 3.

[83] E. Gentleman, R. J. Swain, N. D. Evans, S. Boonrungsiman, G. Jell, M. D. Ball, T. A. V. Shean, M. L. Oyen, A. Porter, M. M. Stevens, Nat. Mater. 2009; 8, 763.

[84] E. Hase, O. Matsubara, T. Minamikawa, K. Sato, T. Yasui, Appl. Opt. 2016; 55, 3261.

[85] R. Ozasa, A. Matsugaki, Y. Isobe, T. Saku, H.-S. Yun, T. Nakano, J. Biomed. Mater. Res., Part A. 2018; $106,360$.

[86] Y. Uto, S. Kuroshima, T. Nakano, T. Ishimoto, N. Inaba, Y. Uchida, T. Sawase, PLoS One 2017; 12. 
(a)

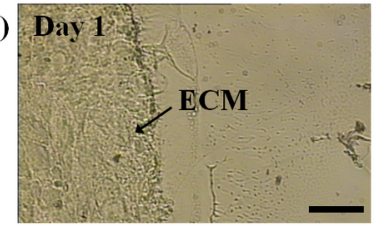

(c) Dinit

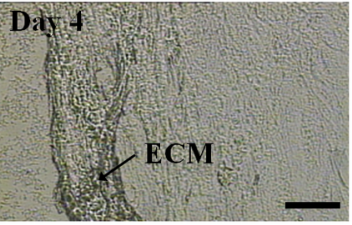

(e)

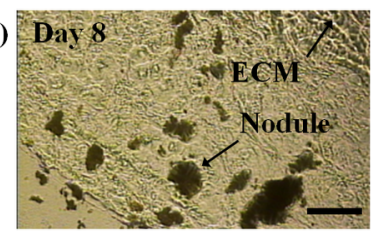

(g) Day 14

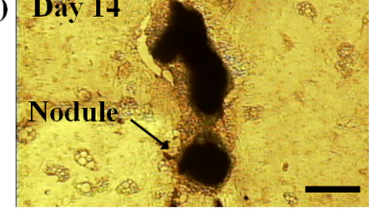

(i) Das 1

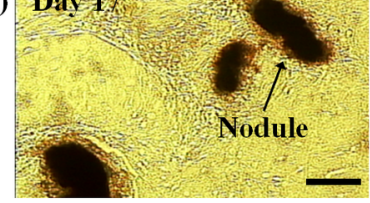

(k) Bar 25

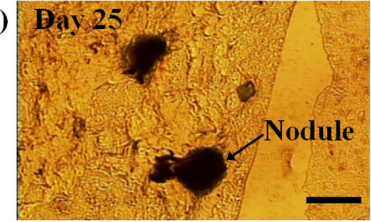

(m)

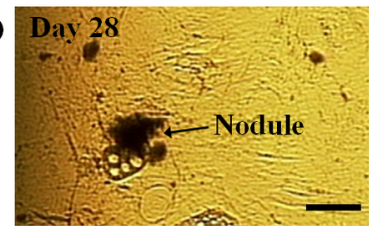

(b) Day 1

(d) Day $4 \quad 1002$

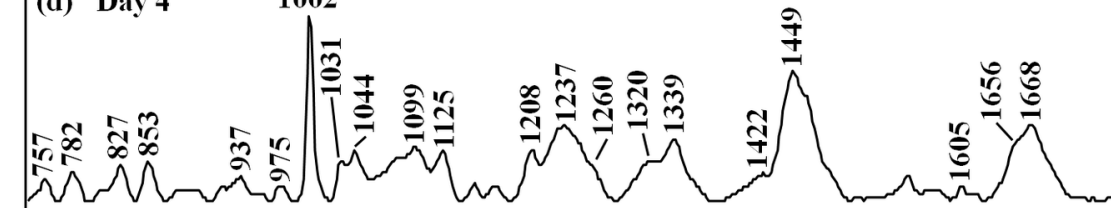

(f) Day $8 \quad 958 \quad$--- ECM

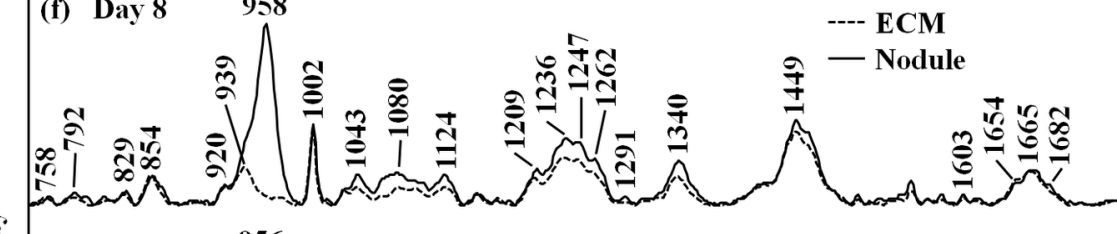
(h) Day $14 \quad 956$

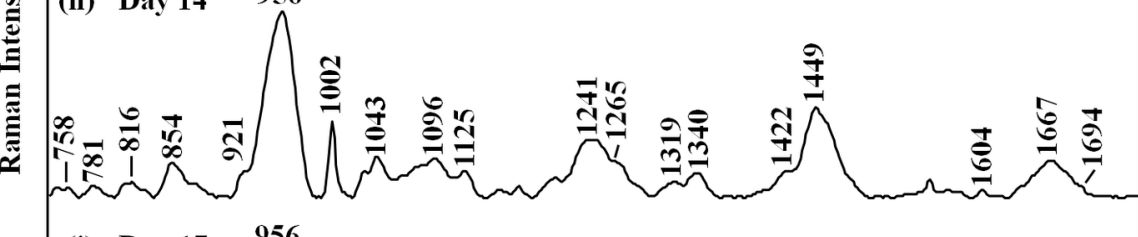
(j) Day $17 \quad 956$

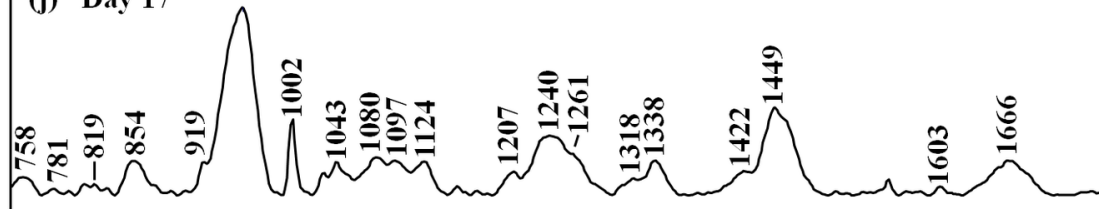

(l) Day $25 \quad 957$
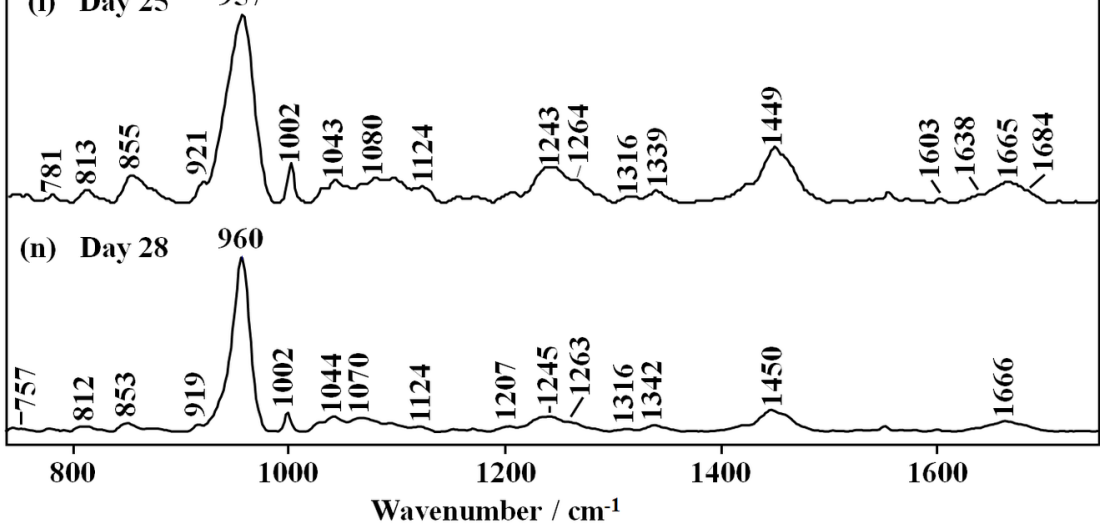

JRS_5521_F1.tif 

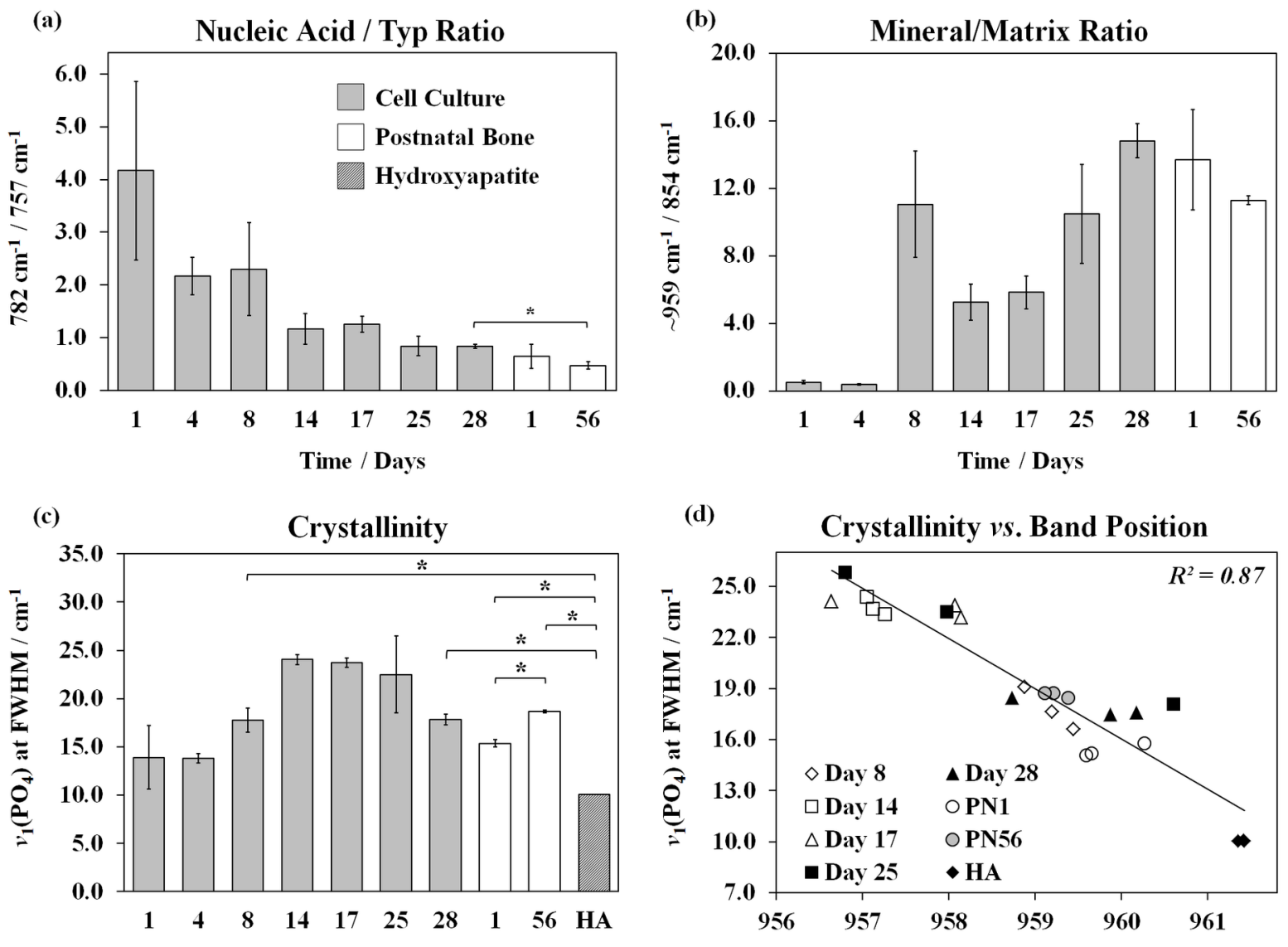

(d) Crystallinity vs. Band Position
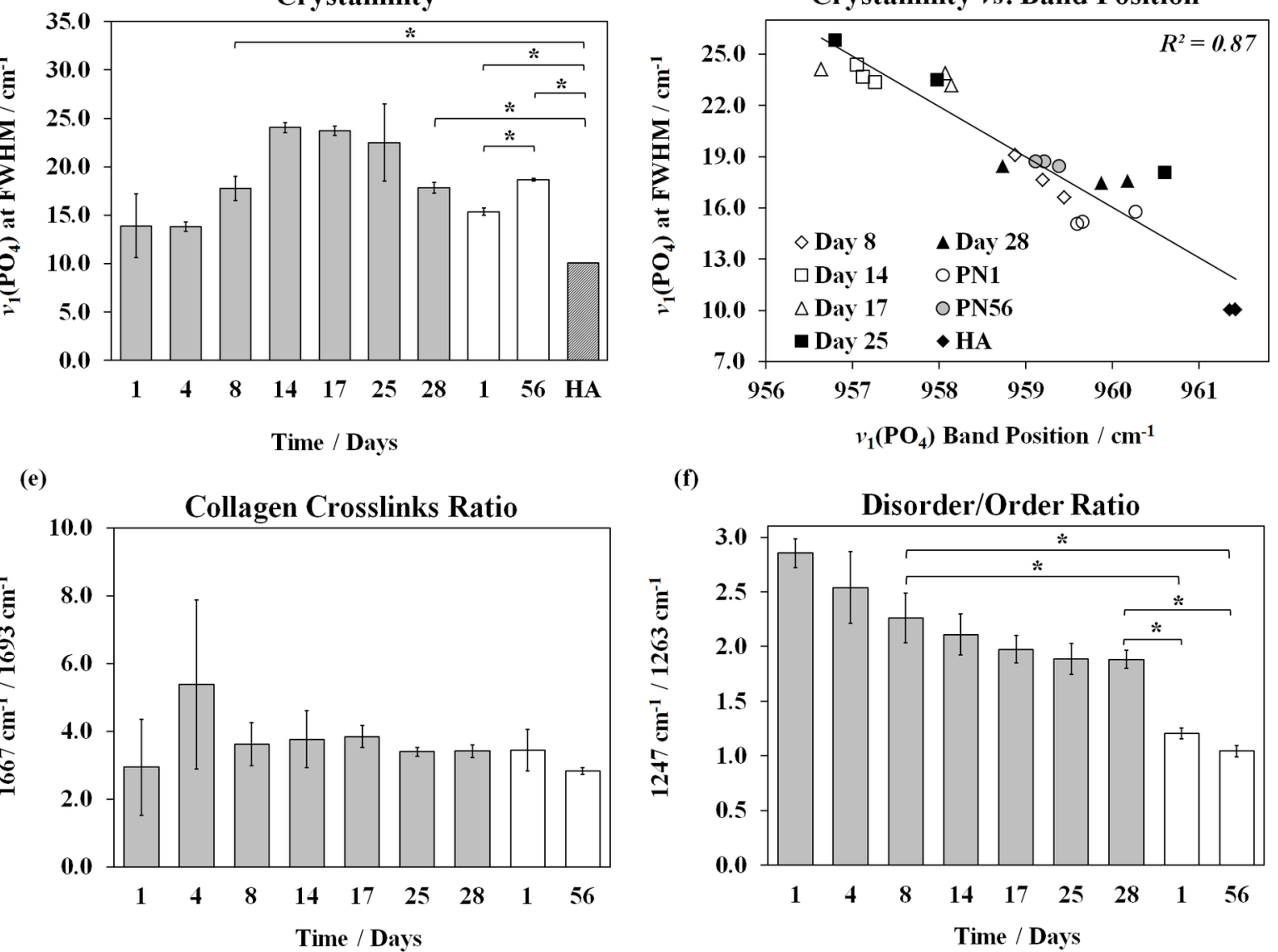

(f)

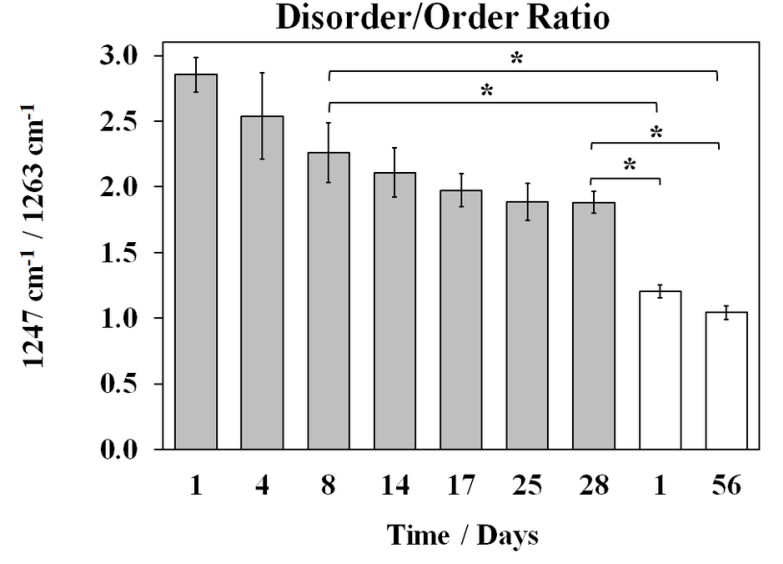

JRS_5521_F2.tif 


\section{Supporting Information - TOC Entry}

Bone quality assessment of osteogenic cell cultures by Raman microscopy

Gurjit S. Mandair, ${ }^{a^{*}}$ Pieter Steenhuis, ${ }^{a}$ Michael A. Ignelzi (Jr), ${ }^{b}$ and Michael D. Morris ${ }^{c}$

${ }^{a}$ Department of Biologic and Materials Sciences, School of Dentistry, University of Michigan, Ann Arbor, Michigan, 48109, USA

${ }^{b}$ Department of Orthodontics and Pediatric Dentistry, School of Dentistry, The University of North Carolina, Chapel Hill, North Carolina, 27599, USA

${ }^{\mathrm{c}}$ Department of Chemistry, University of Michigan, Ann Arbor, Michigan, 48109, USA

*Corresponding Author.

\section{Graphical Table of Content}

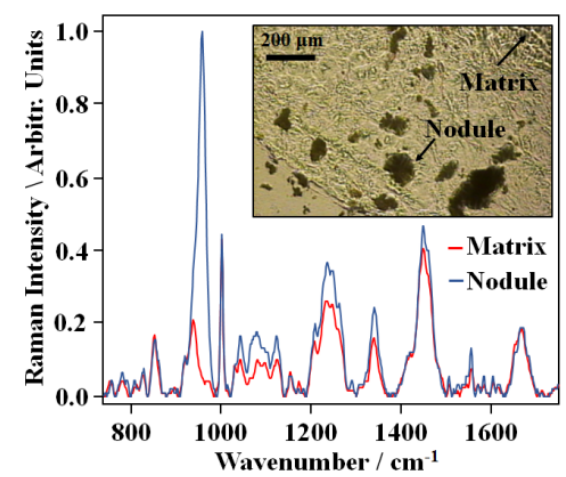

In this Raman spectroscopic study, we examined the quality of bone formed in vitro by fetal mouse calvarial stem/progenitor cells under osteogenic differentiation conditions. We characterized bone mineral and matrix cell culture components and detected the presence of lipid and glycosaminoglycan-like components. Bone formed in vitro at day-28 was similar to 1-day old postnatal mouse calvarial bone in terms of mineralization, mineral crystallinity, and collagen crosslink ratios, but differed in the degree of collagen fibril order. 
